\title{
Primary Hyperaldosteronism: An Unusual but not a Rare Entity
}

\author{
${ }^{1} \mathrm{GS}$ Karthik, ${ }^{2} \mathrm{~B}$ Dixit, ${ }^{3} \mathrm{PC}$ Rath
}

\begin{abstract}
A 36 years old gentleman presented to hospital with symptoms of viral illness. In addition to fever, he was found to have blood pressure of $240 / 160 \mathrm{~mm} \mathrm{Hg}$ which was confirmed by repeated measurements. There was no evidence of target organ damage. His febrile illness turned out to be due to swine flu. Due to severe hypertension, he was admitted to the intensive care unit (ICU) for parenteral antihypertensive drug therapy. He had unexplained severe hypokalemia and metabolic alkalosis. The possibility of primary hyperaldosteronism was considered, plasma aldosterone level was high and plasma renin activity was low, confirming the (biochemical) diagnosis of hyperaldosteronism. He underwent additional work-up and was given specific antihypertensive drugs. The case illustrates classical features of primary hyperaldosteronism, diagnostic and therapeutic considerations.
\end{abstract}

Keywords: Adrenal glands, Aldosterone-renin ratio, Hypertension, Hypokalemia, Primary hyperaldosteronism.

How to cite this article: Karthik GS, Dixit B, Rath PC. Primary Hyperaldosteronism: An Unusual but not a Rare Entity. Hypertens J 2015;1(2):118-120.

\section{Source of support: Nil}

\section{Conflict of interest: None}

\section{INTRODUCTION}

Systemic hypertension is a common risk factor for cardiovascular disease (CVD), premature morbidity, disability, and excessive mortality. Of all the contributing factors for CVD in India (and globally), hypertension is widely prevalent. Despite the decades of professional and public education about hypertension, the condition is under diagnosed and under treated. Consequently, a large proportion of patients, blood pressure is not under control and hence poses a threat to public health.

\section{${ }^{1}$ Resident, ${ }^{2}$ Junior Consultant, ${ }^{3}$ Senior Consultant \\ ${ }^{1}$ Department of Internal Medicine, Apollo Health City Hyderabad, Telangana, India \\ ${ }^{2}$ Department of Cardiology, Apollo Hospital, Jubilee Hills Hyderabad, Telangana, India \\ ${ }^{3}$ Department of Cardiology, Apollo Health City, Hyderabad Telangana, India}

Corresponding Author: GS Karthik, Resident, Department of Internal Medicine, Apollo Health City, Hyderabad, Telangana India, Phone: 08500668878, e-mail: drkarthik05@gmail.com
An overwhelming majority of patients with hypertension have 'primary' type, wherein a specific underlying cause is not identified. A small percentage (about 5\%) have 'secondary' hypertension wherein an underlying cause for blood pressure elevation is identified. In the secondary forms of hypertension, some are curable by correcting the underlying reason while in others blood pressure improves with 'specific' medical treatment to counter the causative mechanism. Primary aldosteronism (PA), also called hyperaldosteronism is an uncommon cause of secondary hypertension occurring in about $1 \%$ of all patients. Some believe that the incidence is much higher due to improved diagnostic methods. The manifestations of PA comprise of-hypertension, (inappropriate) hypokalemia, low plasma renin activity and high aldosterone levels. ${ }^{1-5}$ The specific treatment of PA depends on the sub-type responsible for the disease. We present a case of PA detected accidentally in the hospital setting. Primary aldosteronism is a result of spontaneous excessive production of aldosterone by the glomerular zone of the adrenal glands.

\section{CASE REPORT}

A 36 years old gentleman presented to our hospital with symptoms of upper respiratory infection (cough, cold and fever). Examination in the emerging room was indicative of possible viral syndrome, but he was admitted to the intensive care unit (ICU) because of concomitant severe hypertension. Blood pressure level was consistently $>240 / 160 \mathrm{~mm}$ Hg. He had no cardiovascular, neurological, or renal complaints. As far as hypertension was concerned, he had no symptoms and he was unaware of the condition. The febrile illness was confirmed as Swine Flu but his blood pressure levels remained elevated. He was given intravenous nitroglycerine for blood pressure control.

Cardiovascular examination was normal. Electrocardiograph and echocardiogram showed left ventricular hypertrophy (LVH). Laboratory tests showed a creatinine level of $1.3 \mathrm{mg} / \mathrm{dl}$, serum sodium was $140 \mathrm{mEq} / \mathrm{l}$ and potassium was $2.8 \mathrm{mEq} / \mathrm{l}$. Arterial blood gas results showed metabolic alkalosis. Repeat electrolyte results showed persistent hypokalemia $(<3.0 \mathrm{mEq} / \mathrm{l})$; he was not any diuretics and had no history of vomiting/ diarrhea, etc. Due to severe unexplained hypokalemia, 
Primary Hyperaldosteronism: An Unusual but not a Rare Entity

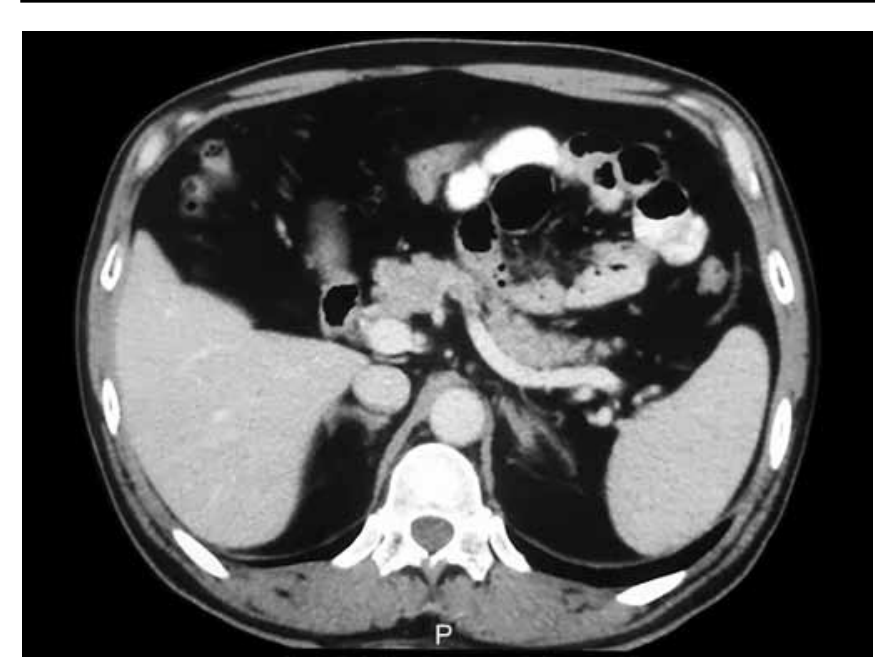

Fig. 1: Computed tomography scan showing bilateral adrenal enlargement

PA was suspected and appropriate biochemical tests were done. Serum aldosterone was high-144.50 pg/ml and plasma renin was low- $0.64 \mathrm{mg} / \mathrm{ml}$. In view of very high aldosterone renin ratio, the diagnostic of PA seemed likely; computed tomography (CT) scan (with thin cuts) showed bilaterally enlarged 'bulky' adrenal glands with no evidence of a discrete mass (Fig. 1). Kidneys and renal arteries was normal. The clinical diagnosis of PA due to bilateral adrenal hyperplasia was made and he was started on aldosterone antagonist $25 \mathrm{mg}$ twice daily in addition to cilnidipine $10 \mathrm{mg}$ bd, and nebivolol $5 \mathrm{mg}$ bd. Within 4 days of starting spironolactone, his aldosterone level came down to $69.34 \mathrm{pg} / \mathrm{ml}$ and renin level role to $2.05 \mathrm{mg} / \mathrm{ml}$. He was maintained on anti-hypertensive drugs plus spironolactone for blood pressure and potassium control. After 4 to 6 weeks of outpatient follow-up, his blood pressure and potassium remained normal on spironolactone plus other non-diuretic antihypertensive drugs.

\section{DISCUSSION}

Secondary forms of hypertension constitute only a small number in the vast ocean of patients with hypertension. Although unusual, secondary causes of hypertension by no means are rare in clinical practice. It is important to recognize secondary forms of hypertension, because specific medical or corrective treatment reverses the disorder. When the pathophysiology of a secondary cause is offset by 'specific' therapy, blood pressure shows remarkable improvement and in some patients can be curative. The suspicion of a secondary hypertension depends on the presenting clinical features and abnormal laboratory findings.

This case report represents a typical patient unprovoked manifestations of PA—hypertension, hypokalemia,
Table 1: Features of primary aldosteronism

1. Hypertension

2. Unprovoked, unexplained hypokalemia

3. High normal serum sodium, metabolic alkalosis

4. $\uparrow$ Aldosterone level

5. $\downarrow$ Renin activity

metabolic alkalosis, low plasma renin activity and high aldosterone level. Whenever a patient with hypertension demonstrates unexplained and inappropriate hypokalemia, primary aldosteronism should be considered in the differential diagnosis. Upon confirmation of hypokalemia (by repeat testing), the possibility of primary aldosteronism should be pursued. The biochemical hallmarks of primary aldosteronism are suppressed renin and elevated aldosterone levels. ${ }^{6-8}$ One should remember that increased renin with elevated aldosterone level is symbolic of 'secondary' aldosteronism - diuretic use, volume depletion, vasodilatory drugs, and renal ischemia. However, suppressed renin and high aldosterone are pathognomonic of primary aldosteronism in a patient with hypertension and unexplained hypokalemia (Table 1).

Once the biochemical diagnosis of primary aldosteronism is made, the next diagnostic step is to determine if the adrenal disease is unilateral (adenoma) or bilateral (hyperplasia). The former is best managed by surgical removal of affected gland whereas the latter is best managed by chronic medical therapy inclusive of an aldosterone antagonist (spironolactone). ${ }^{9-11}$ It should be kept in mind that an aldosterone producing adenoma can be treated medically if surgery is not possible but a bilateral adrenal hyperplasia should always be managed with medical therapy only; surgery is not recommended.

A precisely done CT scan of adrenal glands (with small thin cuts) and/or magnetic resonance imaging (MRI) should suffice in the radiological localization of primary aldosteronism. Due to technical difficulties and challenges in locating right adrenal vein, we do not recommend adrenal vein catheterization for diagnostic purpose. It is best to make therapeutic plans and followup on the basis of well performed CT or MRI of adrenal glands. Similarly, adrenal gland scintigraphy is not generally required to localize primary aldosteronism. ${ }^{12}$

In summary, primary aldosteronism is an unusual cause of hypertension. But it is amenable to specific

Table 2: Electrolytes at baseline and after spironolactone therapy

\begin{tabular}{lll}
\hline & $\begin{array}{l}\text { Before } \\
\text { spironolactone }\end{array}$ & $\begin{array}{l}\text { After } \\
\text { spironolactone }\end{array}$ \\
\hline Sodium $(\mathrm{mEq} / \mathrm{l})$ & 140 & 143 \\
Potassium $(\mathrm{mEq} / \mathrm{l})$ & 2.8 & 4.8 \\
\hline
\end{tabular}


surgical or medical therapy which ameliorates hypokalemia and improves the blood pressure control as was demonstrated in our patient (Table 2). Hypertension can be severe in patients with primary aldosteronism and can cause target organ damage. ${ }^{13,14}$ The clinical diagnosis is suspected on the basis of unexplained hypokalemia in a patient with hypertension and confirmed on the basis of unexplained hypokalemia in a patient with hypertension and the confirmed on the basis of high aldosterone; renin ratio and radiological findings on a CT scan (thin slice) or MRI of the adrenal glands. Depending on the unilaterality or bilaterality of the adrenal gland abnormality, specific medical or surgical therapy is planned which cures hypokalemia and improves or cures hypertension.

\section{ACKNOWLEDGMENT}

The authors thank Dr C Venkata S Ram for the referral of the patient and Ms N Madhavi Latha for her secretarial/ editorial assistance in the preparation of this manuscript.

\section{REFERENCES}

1. Ram CVS. Primary aldosteronism—recognition and management. Rhode Island Med J 1977;60(6):301-305.

2. Ram CVS. Primary aldosteronism-its role in hypertension. Consultant 1981;21:2-11.

3. Ram CVS. Hypertension: when to suspect underlying pheochromocytoma or aldosteronism? Consultant 1996;33: 147-153.
4. Lim PO, Rodgers P, Cardale K, et al. Potentially high prevalence of primary aldosteronism in a primary-care population. Lancet 1999 Jan 2;353(9146):40.

5. Loh KC, Koay ES, Khaw MC, et al. Prevalence of primary aldosteronism among Asian hypertensive patients in Singapore. J Clin Endocrinol Metab 2000;85(8):2854-2859.

6. Stowasser M, Gordon RD. The aldosterone-renin ratio for screening for primary aldosteronism. Endocrinologist 2004;14:267-276.

7. Stowasser M, Gordon RD. Primary aldosteronism: careful investigation is essential and rewarding. Mol Cell Endocrinol 2004;217(1-2):33-39.

8. Oliveri O, Ciacciarelli A, Signorelli D, et al. Aldosterone to renin ratio in a primary care setting: the Bussolengo study. J Clin Endocrinol Metabol 2004;89(9):4221-4226.

9. Rutherford JC, Taylor WL, Stowasser M, et al. Success of surgery in primary aldosteronism judged by residual autonomous aldosterone production. World J Surg 1998;22(12):1243-1245.

10. Rutherford JC, Stowasser M, Tunny TJ, et al. Laparoscopic adrenalectomy. World J Surg 1996;20(7):758-760.

11. Parthasarathy HK, Ménard J, White WB, et al. A double-blind, randomized study comparing the antihypertensive effect of eplerenone and spironolactone in patients with hypertension and evidence of primary aldosteronism. J Hypertens 2011;29(5):980-990.

12. Stowasser M, Gordon RD, Rutherford JC, et al. Diagnosis and management of primary aldosteronism. J Renin Angiotensin Aldosterone Syst 2001;2(3):156-169.

13. Rossi GP, Sacchetto A, Visentin P, et al. Changes in left ventricular anatomy and function in hypertension and primary aldosteronism. Hypertens 1996;27(5):1039-1045.

14. Rossi GP, Bernini G, Desideri G, et al. Renal damage in primary aldosteronism: results of the PAPY study. Hypertens 2006;48(2):232-238. 